\title{
Causes of lowered family consent rate for organ donation
}

\author{
Eunsuk Yu ${ }^{1}$, Yukyoung Son ${ }^{2}$, Kyeonghee Han ${ }^{1}$, Myounghwa Lee ${ }^{1}$, Yuri Chong ${ }^{1}$, Youngsoon Jeong ${ }^{1}$, Jeongrim Lee ${ }^{1}$, \\ Wonhyun $\mathrm{Cho}^{2}$
}

\footnotetext{
${ }^{1}$ Donation Information Division, Korea Organ Donation Agency, Seoul, Korea

${ }^{2}$ Korea Organ Donation Agency, Seoul, Korea
}

Background: The number of deceased donors that have increased annually until 2016 has started to decline in the last three years. This study therefore intends to analyze the trend of potential brain death reported to Korea Organ Donation Agency (KODA) and use the analysis results as a basic data for the activation of organ donation.

Methods: A comparative analysis was performed for the first period (P1: 2014 to 2016) where the number of donations continued to increase and the second period (P2: 2017 to 2019) that showed decline in donations compared to 2016.

Results: The cases of potential brain death reported to KODA was 5,548 in P1 and 7,126 in P2, a $28.4 \%$ increase from the previous period. Among these, the cases of medically suitable for organ donation increased by $36.5 \%$, from 4,053 in P1 to 5,534 in P2. Decreased the consent rate from $52.9 \%$ in $\mathrm{P} 1$ to $37.2 \%$ in $\mathrm{P} 2$. The discontinuation of donation process even after family consent increased by $17.6 \%$ (from 74 cases in P1 to 87 cases in P2), mostly due to legal issues and death before the judgment of brain death.

Conclusions: The decrease in families' consent for organ donation turned out to be the biggest cause of declining donation. The major reasons for refusal to donation such as can be attributed to the lack of understanding of the medical state of brain death, a negative image of sharing and donation that is pervasive in Korean society, and the distrust between community members. Therefore, there is a need for education and promotion at a national level to enhance the awareness of the value of life and to encourage the public to practice the value of sharing.

Corresponding author: Eunsuk Yu

E-mail: es.ryw@koda1458.kr

(c) The Korean Society for Transplantation

This is an Open Access article distributed under the terms of the Creative Commons Attribution Non-Commercial License (http://creativecommons.org/licenses/by-nc/4.0/) which permits unrestricted non-commercial use, distribution, and reproduction in any medium, provided the original work is properly cited. 